Research Article

\title{
Comparison of Calcaneal Taping and Low-Dye Taping for the Short-Term Management of Plantar Fasciitis
}

\author{
Nitin Sharma', Kalpana Zutshi², D Wardhan ${ }^{3}$ \\ ${ }^{1}$ MPT Sports Medicine, Senior Clinical Physiotherapist, New Delhi, India. \\ ${ }^{2}$ Associate Professor, Dept. of Rehabilitation Sciences, SNSAH, Jamia Hamdard, New Delhi, India. \\ ${ }^{3}$ Senior Physiotherapist, All India Institute of Medical Sciences, AIIMS, New Delhi, India. \\ DOI: https://doi.org/10.24321/2454.325X.202016
}

I $\quad \begin{array}{lll}\mathbf{N} & \mathbf{F} & \mathbf{O}\end{array}$

\section{Corresponding Author:}

Kalpana Zutshi, Dept. of Rehabilitation Sciences, SNSAH, Jamia Hamdard, New Delhi, India.

E-mail Id:

zutshi.kalpana@gmail.com

Orcid Id:

https://orcid.org/0000-0002-3494-5665

How to cite this article:

Sharma N, Zutshi K, Wardhan D. Comparison of Calcaneal Taping and Low-Dye Taping for the Short-Term Management of Plantar Fasciitis. Int J Preven Curat Comm Med 2020; 6(4): 19-25.

Date of Submission: 2021-01-29

Date of Acceptance: 2021-03-02

\section{$\begin{array}{llllllll}\mathbf{A} & \mathbf{B} & \mathbf{S} & \mathbf{T} & \mathbf{R} & \mathbf{A} & \mathbf{C} & \mathbf{T}\end{array}$}

Background: Plantar fasciitis is one of the most common causes of heel and foot pain. Physical therapists have applied many techniques in an attempt to relieve the symptoms of plantar fasciitis, including various taping methods for which there is little existing evidence. Purpose of the study is to compare the effects of 2 different taping techniques in shortterm management of plantar fasciitis. Study design was randomized pre- and post-test different subject experimental design.

Methods and Measure: Subjects $(n=30)$ were randomly assigned into 3 groups: (A) calcaneal taping and conventional treatment,(B) low-dye taping and conventional treatment, $(C)$ conventional treatment only. Visual analog scale (VAS) for first-step pain and foot function index scale (FFI) for functional activities were measured pretreatment, $4^{\text {th }}$ day and after 1 week of treatment, $7^{\text {th }}$ day ( post-treatment).

Result: Follow up analysis revealed that calcaneal and low-dye taping showed greater improvement on 2 nd and 3rd session compared to conventional treatment.

Conclusion: Subjects treated with calcaneal and low-dye taping along with ultrasound and passive stretching showed an additional and more significant improvement as compared to ultrasound and passive stretching only and also there was no significant difference found between calcaneal and low-dye taping groups in terms of reduction of pain on VAS and FFI. Hence, it can be concluded that both calcaneal and low-dye taping techniques are effective therapeutic option in shortterm treatment of plantar fasciitis.

Keywords: Plantar Fasciitis, Calcaneal Taping, Low-Dye Taping

\section{Introduction}

Plantar Fasciitis (PF) or commonly the heel pain syndrome is a frequent cause of heel pain in athletes as well as non-sports person. ${ }^{1,2}$ This is a common overuse syndrome involving an inflammation reaction at insertion of plantar 
fascia to calcaneous ${ }^{3,4}$ following tensile overload to plantar fascia, ${ }^{1}$ although it is also proved that plantar fasciitis is degenerative process without inflammation and not a fasciitis. ${ }^{5}$ Plantar fasciitis is most prevalent in runners; ${ }^{3,6}$ people active in other sports that require repetitive push-off motions, such as tennis, basketball, soccer and gymnastic are also involved. ${ }^{1}$ In older people, plantar fasciitis consists of degenerative micro-tears of medial band of plantar fascia and in younger people, who are athletes and runners, plantar fasciitis is an overuse injury. ${ }^{2}$ The chief initial complaint is typically a sharp pain in the inner aspect of foot with first step in morning. ${ }^{7,8}$

There are various aetiological factors resulting in PF and these are classified as being biomechanical, environmental and anatomical. ${ }^{6}$ Biomechanical approaches emphasize the importance of proper control of hind foot motion so that excessive pronation does not occur. ${ }^{6}$ Kwong et al ${ }^{9}$ shows that pronation causes an increase in tensile stress to plantar fascia insertion. Tight posterior tendoachilles results in excessive stretching of plantar fascia and resultant range of motion deficits. ${ }^{2,10}$

In their study of functional biomechanics of athletes with plantar fasciitis, Kibler et al $^{6}$ found that a tight triceps surae muscle creates a valgus (weight bearing) heel position at heel strike restricting supination and dorsiflexion of hind foot. Riddle and Freeman ${ }^{11}$ previously concluded that tight triceps surae tether the calacneus in valgus (weight bearing) position at heel strike thus leading to a functional pronation.

Plantar fascia taping is widely used to add support and reduce stress on plantar fascia pain ligaments as both ways to relive pain from plantar fasciitis. ${ }^{12,13}$ Low-dye is taping widely used in PF and shows that there is significant reduction in pain associated with $\mathrm{PF}^{11,12,14}$ Low-dye taping involves application of tape on plantar aspect of foot without crossing the ankle. ${ }^{15}$ There are a variety of LD taping methods, all modified from the original technique described by $\mathrm{Dr}$ Ralph dye identified in literature. ${ }^{16}$ In calcaneal taping, with biomechanical point of view, a decreased height of longitudinal arch of foot is caused by eversion of calcaneous and plantar flexion/ adduction of talus; theoretically, this technique places foot in an improved biomechanical position by repositioning calcaneal alignment closer to neutral and increasing medial longitudinal arch height, thus reducing stress and subsequent micro-traumas to plantar fascia. It is the main focus on biomechanics at the rear-foot versus mid-foot that makes this technique unique. ${ }^{17}$ The purpose of this study was to find out any difference between calcaneal taping and low-dye taping arch supporting taping technique in terms of relieving first pain in the morning and improving functional activity of foot based on foot function index.

\section{Methodology}

Study Design: Pretest-posttest group design.

Statistical Tool: Bonferronic post hoc test was used to analyze the day wise difference of VAS and FFI score.

Study Duration: 7 days

Place of Study: Jamia Hamdard University, New Delhi.

\section{Inclusion and Exclusion Criteria}

\section{Inclusion Criteria ${ }^{14,19}$}

- Male and female between ages of 35 to 45 years.

- Localized pain at plantar heel or plantar surface of mid foot with diagnosis of plantar fasciitis.

- Pain worsens when standing or walking after rest.

- Pain in heel on first step in the morning.

- Clinically diagnosed symptoms for more than or equal to 4 weeks.

\section{Exclusion Criteria ${ }^{14,19}$}

- Any infected condition of foot, tumor, and calcaneal fracture.

- Congenital deformity of foot or ankle.

- Impaired circulation to lower extremity.

- $\quad$ Referred pain due to sciatica and other neurological disorders.

- Corticosteroids injections in heel within past 3 months.

- Any allergy to taping as assessed within first 24 hours of treatment.

\section{Ethical Approval}

Written informed consent was obtained from the participants of the study.

\section{Subjects}

Subjects in this study were 30 , both males and females randomly selected and divided equally $(n=10)$ into 3 groups.

\section{Study Procedure}

Subjects were assigned randomly to one of the 3 groups. Subjects in group $A(n=10)$ received calcaneal taping along with pulse ultrasound and passive stretching of ankle plantar flexors and plantar fascia; group $B(n=10)$ received low-dye taping along with pulse ultrasound and passive stretching of ankle plantar flexors and plantar fascia, group C $(n=10)$ received only pulsed ultrasound and passive stretching of ankle plantar flexors and plantar fascia. All 3 groups were treated in PT department. Each subject selected in study underwent the following procedures at base line:

- A questionnaire for recording of demographic information.

- VAS for pain measurement.

- $\quad \mathrm{FFI}$ (Foot Function Index) for self reported measure of 
pain, function and activity level associated with foot dysfunction consisting of 23 items.

All 3 groups were treated in PT department for 7 consecutive days. On $7^{\text {th }}$ day, all subjects completed VAS \&FFI questionnaire for the $3^{\text {rd }}$ time. The intervention programme for 3 groups consisted of:

- Passive stretching of plantar flexors and plantar fascia ${ }^{17,18}$

- Ultrasound with output of $1 \mathrm{w} / \mathrm{cm}$ for $5 \mathrm{~min}$ using pulsed mode 1:4 ratio with frequency of $1 \mathrm{MHz}$ for 7 sittings for 7 consecutive days. ${ }^{19}$

- Passive stretching program for all three groups of the ankle plantar flexors and plantar fascia in physical therapy. Soleus muscle was stretched with knee flexed and gastronomies muscle stretched with knee extended, over pressure was placed upon bottom of foot while ankle was in dorsiflexion. A passive stretch was also applied to big toe flexor to incorporate stretch to plantar fascia. Subjects in all 3 groups were instructed not to perform these stretches at home.

\section{Protocol for Group A (Calcaneal Taping, Ultrasound and Passive Stretching Exercise) $)^{17-19}$}

Cover roll stretch bandage was applied to clean and dry skin surface, then covered with leukotape. Once cover roll is applied, taping with leukotape is followed. Piece 1 is applied just distal to the lateral malleolus, pulling the calcaneum medially and attached to medial aspect of foot distal to medial malleolus. Piece 2 and 3 followed the same pattern with overlap of approximately one third of tape width moving in distal direction. Piece 4 went around the back of heel strapping around posterior aspect of calcaneum and anchoring distal end of medial malleolus. Piece 4 applied in-order to serve as an anchor for the first 3 pieces.

Group B received (Low-Dye Arch Supporting Taping, Ultrasound and Passive Stretching) $)^{18-20}$

The LD taping technique involved use of 10 strips of 5 centimeters wide, brown, rigid adhesive tape. With ankle in neutral, plantar grade position, a proximal anchor under the heel and distal anchor under metatarsal heads were applied. Three longitudinal strips of tape were then applied from the metatarsophalangeal joints to heel using a mild downward (distal-to-proximal) pull, starting with central strip, medial strip and finally lateral strip.

LD taping technique also included applying 3 transverse strips under plantar aspect of foot using strong supinating pressure. The first transverse strip is applied immediately distal to the heel across mid-foot from lateral to medial side of the foot. The second and third transverse strips were applied distally and overlaid the previous strip by one third. The technique will complete with a proximal anchor and distal anchor.

\section{Group C Received only Conventional Treatment which Included}

- Passive stretching of plantar flexors and plantar fascia ${ }^{18,21}$

- Ultrasound with output of $1 \mathrm{w} / \mathrm{cm}$ for 5 min using a pulse mode 1:4 ratio with frequency of $1 \mathrm{MHz}$ for 7 sittings for 7 consecutive days ${ }^{19}$

All three groups $(A, B, C)$ received ultrasound with output of $1 \mathrm{~W} / \mathrm{cm}$ for 5 min using pulsed mode $1: 4$ ratio with frequency of $1 \mathrm{Mhz}$ was applied, then received passive stretching of ankle plantar flexors and plantar fascia for 7 consecutive days. Soleus muscle was stretched with the knee flexed and gastrocnemius muscle was stretched with knee extended, overpressure was placed upon the bottom of the foot while toe ankle was in dorsiflexion. A passive stretch was applied to big toe flexors to incorporate stretch to plantar fascia. The stretch to both muscle groups was performed for 3 repetitions, each held for 30 seconds ${ }^{18}$ with 1-2 min rest period between each set.

Group A also received calcaneal taping which was changed after $24 \mathrm{hr}$ for 7 consecutive days and group B received lowdye taping which was changed after $24 \mathrm{hr}$ for 7 consecutive days, whereas group $C$ received only ultrasound and passive stretching exercise for seven consecutive days. ${ }^{18,22}$

Outcomes Measures: A visual analog scale (VAS) ${ }^{23}$ for firststep pain and foot function index scale $(\mathrm{FFI})^{24}$ for functional activities were measured pretreatment on $4^{\text {th }}$ day and after 1 week of treatment, and $7^{\text {th }}$ day ( post-treatment). Functional assessment was done by using foot function index.

\section{Data Analysis}

For each testing procedure verbal description was given, data was collected in a quiet room under similar conditions for each subjects by same investigator, data was collected in the collection form (appendix B) along with the other details of the patient, first the base line value for VAS and $\mathrm{FFI}$ were recorded and then on day 4 and day 7 prior to intervention for analysis. Data were managed on an excel spread sheet, the statistics were performed using SPSS (version17) a significant level of $p<0.05$ was fixed.

Bonferroni post hoc test was used to analyze the day wise difference of VAS and FFI scores within group through day 1,4 and 7 which showed significant $p$ values for each group. The difference between the VAS and FFI scores in all three groups was analyzed by using ANNOVA with repetitive measure, which showed significant $f$ and $p$ values for the VAS and ROM of the groups.

\section{Result}

Table 1, shows the demographic details of group A, B and C. The mean and standard deviation age, weight, and height of subjects in group $A, B$, and $C$ reflected no significant difference. 
Inter-group data analysis revealed significant improvement in the FFI scores of G-A and G-C subjects and in G-B and G-C subjects where there was no significant difference between G-A and G-B subjects (Figure 1 ). In VAS score of G-A and G-C subjects and G-B and G-C showed significant difference where there was no significant difference between G-A and G-B subjects (Figure 2).
The within group day-wise data analysis showed significant improvement in both G-A and G-B across all days, in G-C there was significant improvement in day 1 vs 4,1 vs 7 but not any significant difference in day 4 vs 7 (Tables 4 to 6). Bonferroni post-hoc test was used to compare difference in VAS and FFI scores on day 1, 4 and 7 between 3 groups, shown in Tables 2 and 3.

Table I.Baseline physical characteristics, data are mean ( \pm S.D) none of the group difference was significant

\begin{tabular}{|c|c|c|c|}
\hline & Age (Mean \pm SD) & Weight (Mean \pm SD) & Height (Mean \pm SD) \\
\hline Group A & $39.20 \pm 3.32$ & $69.40 \pm 10.99$ & $5.50 \pm 0.182$ \\
\hline Group B & $40.90 \pm 4.28$ & $73.20 \pm 3.99$ & $5.60 \pm 0.267$ \\
\hline Group C & $39.8 \pm 4.64$ & $70.70 \pm 8.51$ & $5.62 \pm 0.293$ \\
\hline
\end{tabular}

Table 2.Comparison of FFI between all three groups after intervention through day I, 4, and 7

\begin{tabular}{|c|c|c|c|c|c|c|}
\hline & \multirow{2}{*}{$G A(N=10)$ Mean $\pm S D$} & \multirow{2}{*}{$\mathrm{GB}(\mathrm{N}=10)$ Mean $\pm S D$} & \multirow{2}{*}{$\mathrm{GC}(\mathrm{N}=10)$ Mean $\pm S D$} & \multicolumn{3}{|c|}{ Bonferroni post-hoc test } \\
\hline & & & & $A$ vs $B$ & A vs $C$ & B vs C \\
\hline FFI 1 & $171.58 \pm 37.82$ & $165.62 \pm 37.82$ & $194.72 \pm 37.82$ & 1.00 & 0.547 & 0.273 \\
\hline FFI 4 & $112.59 \pm 31.94$ & $114.84 \pm 31.94$ & $163.69 \pm 31.94$ & 1.00 & 0.004 & 0.006 \\
\hline FFI 7 & $89.68 \pm 26.46$ & $72.33 \pm 26.46$ & $147.44 \pm 26.46$ & 0.462 & 0.000 & 0.000 \\
\hline
\end{tabular}

Table 3.Comparison of VAS between all three groups after intervention through day I, 4, and 7

\begin{tabular}{|c|c|c|c|c|c|c|}
\hline & \multirow{2}{*}{$\mathrm{GA}(\mathrm{N}=10)$ Mean $\pm S D$} & \multirow{2}{*}{$\mathrm{GB}(\mathrm{N}=10)$ Mean $\pm S D$} & \multirow{2}{*}{$G C(N=10)$ Mean $\pm S D$} & \multicolumn{3}{|c|}{ Bonferroni post hoc test } \\
\hline & & & & $A$ vs $B$ & Avs C & B vs C \\
\hline VAS 1 & $7.2 \pm 0.82$ & $7.3 \pm 0.82$ & $7.65 \pm 0.82$ & 1.00 & 0.694 & 1.00 \\
\hline VAS 4 & $5.05 \pm 1.06$ & $4.75 \pm 1.06$ & $5.8 \pm 1.06$ & 1.00 & 0.378 & 0.107 \\
\hline VAS 7 & $3.65 \pm 1.03$ & $2.7 \pm 1.03$ & $5.45 \pm 1.03$ & 0.149 & 0.002 & 0.000 \\
\hline
\end{tabular}

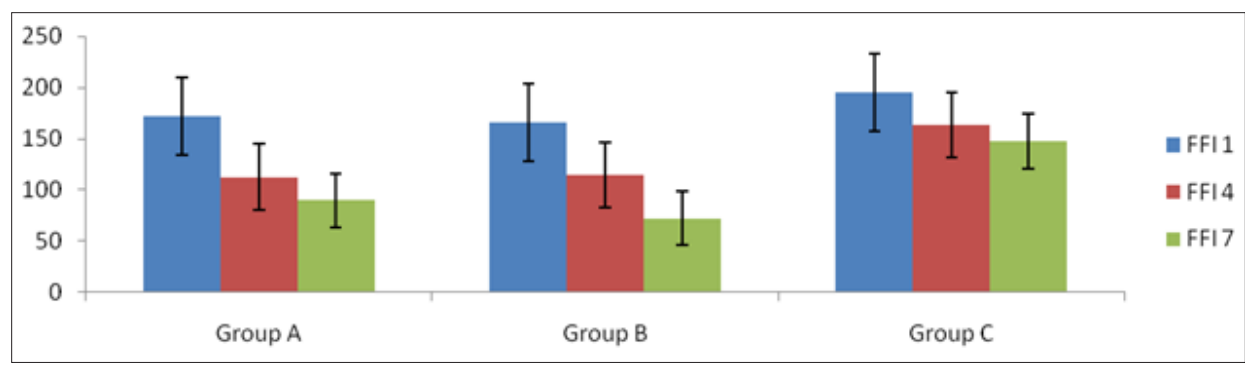

Figure I.Comparison of FFI between all three groups

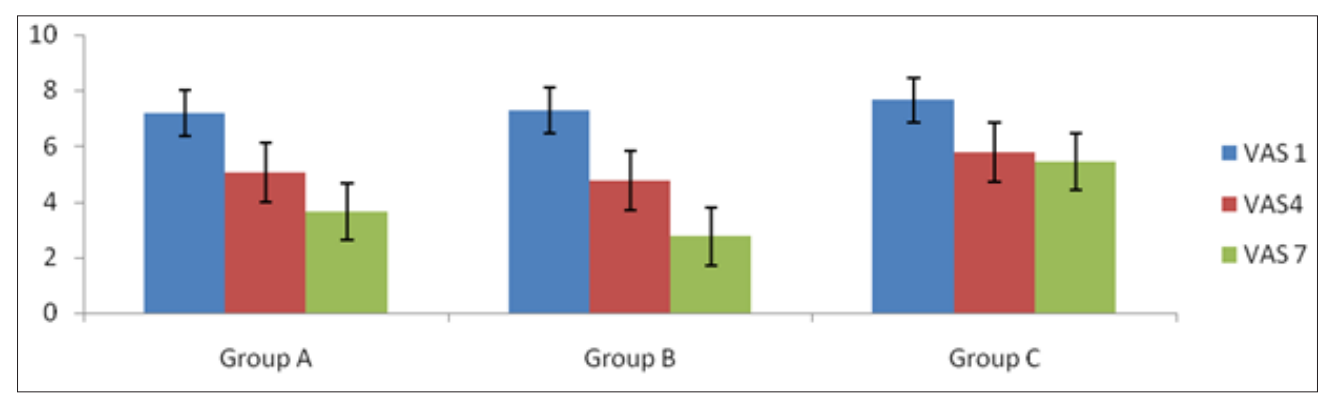

Figure 2.Comparison of VAS between all three groups 
Table.4 Day Wise Comparison of FFI and VAS within Group Analysis for Group

\begin{tabular}{|c|c|c|c|c|c|c|c|c|}
\hline & \multirow{2}{*}{$\begin{array}{c}\text { Day 1 } \\
\text { Mean } \pm \text { SD }\end{array}$} & \multirow{2}{*}{ Day 4 Mean \pm SD } & \multirow{2}{*}{ Day 7 Mean $\pm S D$} & \multicolumn{2}{|c|}{ ANOVA } & \multicolumn{3}{c|}{ Bonferroni post hoc test } \\
\cline { 5 - 9 } & & & F-value & P- value & 1vs4 & 1vs7 & 4vs7 \\
\hline FFI & $171.58 \pm 37.82$ & $112.59 \pm 31.94$ & $89.68 \pm 26.46$ & 9.68 & 0.000 & 0.000 & 0.000 & 0.000 \\
\hline VAS & $7.2 \pm 0.82$ & $5.05 \pm 1.06$ & $3.65 \pm 1.03$ & 7.357 & 0.000 & & & \\
\hline
\end{tabular}

Table 5.Day Wise Comparison of FFI and VAS within Group Analysis For group B

\begin{tabular}{|c|c|c|c|c|c|c|c|c|}
\hline & \multirow{2}{*}{$\begin{array}{c}\text { Day1 } \\
\text { Mean } \pm \text { SD }\end{array}$} & \multirow{2}{*}{$\begin{array}{c}\text { Day4 } \\
\text { Mean } \pm \text { SD }\end{array}$} & \multirow{2}{*}{$\begin{array}{c}\text { Day7 } \\
\text { Mean } \pm \text { SD }\end{array}$} & \multicolumn{2}{|c|}{ ANOVA } & \multicolumn{3}{|c|}{ Bonferroni post hoc test } \\
\hline & & & & F-value & p-value & 1 vs 4 & 1vs 7 & 4vs7 \\
\hline $\mathrm{FFI}$ & $162.62 \pm 37.82$ & $114.84 \pm 31.94$ & $72.33 \pm 26.46$ & 9.68 & 0.000 & \multirow{2}{*}{0.000} & \multirow{2}{*}{0.000} & \multirow{2}{*}{0.000} \\
\hline VAS & $7.3 \pm 0.82$ & $4.75 \pm 1.06$ & $2.7 \pm 1.03$ & 7.357 & 0.000 & & & \\
\hline
\end{tabular}

Table 6.Day Wise comparison of FFI and VAS within Group Analysis for group C

\begin{tabular}{|c|c|c|c|c|c|c|c|c|}
\hline & \multirow{2}{*}{ Day1 Mean $\pm S D$} & \multirow{2}{*}{ Day4 Mean $\pm S D$} & \multirow{2}{*}{ Day7 Mean \pm SD } & \multicolumn{2}{|c|}{ ANOVA } & \multicolumn{3}{|c|}{$\begin{array}{c}\text { Bonferroni post hoc } \\
\text { test }\end{array}$} \\
\hline & & & & F- value & p-value & 1vs4 & 1vs7 & $4 v s 7$ \\
\hline $\mathrm{FFI}$ & $194.72 \pm 37.82$ & $163.69 \pm 31.94$ & $147.44 \pm 26.46$ & 9.68 & 0.000 & \multirow{2}{*}{0} & \multirow{2}{*}{0.00} & \multirow{2}{*}{0.851} \\
\hline VAS & $7.65 \pm 0.82$ & $5.8 \pm 1.06$ & $5.45 \pm 1.03$ & 7.357 & 0.000 & & & \\
\hline
\end{tabular}

\section{Discussion}

The intent of this study was to find out if there was any significant difference between calcaneal and low-dye taping when added with ultrasound and passive stretching of the ankle plantar flexors and plantar fascia in the short-term management of plantar fasciitis.

The findings of this study show that there was no significant difference between the calcaneal and low-dye taping groups on VAS score and FFI scores, both groups however demonstrate significant improvement, across days compared to conventional treatment, also day $7^{\text {th }}$ showed greatest improvement than day $4^{\text {th }}$ and least at day 1 as compared to conventional treatment. At baseline, the ANOVA showed no significant difference among all 3 groups for VAS and FFI scores. Post-treatment, Bonferroni post-hoc test reveled difference between calcaneal taping and conventional treatment (pulse ultrasound and passive stretching ) on day $4^{\text {th }}, 7^{\text {th }}$ for $\mathrm{FFI}$, and for VAS there was significant difference on day $7^{\text {th }}$ between calcaneal taping and conventional treatment and between low-dye and conventional treatment.

This study showed significant improvement in VAS and $\mathrm{FFI}$ scores in the calcaneal and low-dye taping groups as compared to conventional treatment (pulse ultrasound and passive stretching of ankle plantar flexors and plantar fascia). Previous studies have shown both calcaneal taping and low-dye taping technique can be used to provide shortterm (7-10 days) pain relief and significantly reduces the pain associated with plantar fasciitis. ${ }^{5,13,25}$
Calcaneal taping is different from low-dye taping; calcaneal taping technique inverts the heel to raise the medial longitudinal arch of the foot, unlike low-dye taping method that places the tape directly on the arch to support it; taping the calcaneous to prevent excessive pronation and maintaining a more neutral position presumably helps control the height of medial longitudinal arch of the foot, thus taking the force off the plantar fascia. ${ }^{17}$

The findings of this study are consistent with results previously reported that low-dye taping is effective for the short-term treatment of the common symptoms of first step pain in patients with plantar fasciitis.13,14,26

The main proposed mechanism behind the clinical effectiveness of low-dye taping has been restricted rearfoot pronation, ${ }^{31}$ thereby reducing medial loading and increasing lateral loading through the foot. ${ }^{27}$

This study also showed improvement of VAS and FFI score in conventional treatment group (pulse ultrasound and passive stretching of plantar flexors and plantar fascia). These findings are consistent with result previously reported that calf muscle and/or plantar fascia specific stretching can be used to provide short-term pain relief and improvement in calf flexibility. ${ }^{25}$

Digiovanni et al. ${ }^{28}$ concluded that a program of non-weight bearing stretching exercise specific to the plantar fascia is superior to the standard program of weight-bearing Achilles tendon- stretching exercise for the treatment of symptoms of proximal plantar fasciitis. 
Jeffery et al. ${ }^{3}$ strongly emphasizes that stretching exercise, because they effectively decrease the probability of musculotendinous injury to the foot and help reduce soreness of the plantar fascia.

Ryan et $\mathrm{al}^{18}$ study found that two 30 sec bouts of constant, torque passive stretching may be necessary to cause a significant decrease in musculotendinous stiffness of plantar flexors muscles.

Pulsed ultrasound was used to reduce inflammation, perfuse local blood flow and facilitate the removal of the newly formed calcium acetate into the blood and thereby remove it from the localized area of heel pain. ${ }^{29}$ The use of ultrasound for 7 min prior to stretching may be the most effective for increasing ankle dorsiflexion ROM. ${ }^{32}$ However, study of Fay Crawford and Snaith ${ }^{30}$ showed that therapeutic ultrasound at a dosage of $0.5 \mathrm{w} / \mathrm{cm}^{2}, 3 \mathrm{MHz}$, pulse 1:4, for 8 minutes is no more than placebo in the treatment of plantar heel pain.

\section{Relevance to Clinical Practice}

Both calcaneal and low-dye taping bring together two important aspects of clinical care; patient relief and the identification of a long-term solution. While other interventions, such as ultrasound, iontophoresis, and cryotherapy, address the symptoms of plantar heel pain. Taping addresses the one presumed cause of the pathology: poor foot biomechanics. Tapings were utilized before practices and games to encourage a progressive return to sports and limit the aggravation of symptoms. Once the patient had adapted to the new orthotics, the athletic taping was omitted from treatment to evaluate the progressive response. Calcaneal taping technique differs from the low-dye taping technique to mediate pain and function with tape in its ease of application and cost. With only 4 pieces of tape, it is easier and faster for a therapist to apply, and it is less expensive than other techniques using large quantities of tape.

\section{Conclusion}

On the basis of the present study, it can be concluded that conservative treatment approach like physiotherapy in the treatment of plantar fasciitis is beneficial. Although all 3 groups, conventional, calcaneal taping, and low-dye taping have been found to be effective in alleviation of symptoms and associated disability in plantar fasciitis, the subjects treated with calcaneal and low-dye taping along with ultrasound and passive stretching showed an additional and more significant improvement as compared to ultrasound and passive stretching only and also there was no significant difference found between calcaneal and low-dye taping groups in terms of reduction of pain on VAS and FFI. Hence, it can be concluded that both calcaneal and low-dye taping techniques are effective therapeutic options in the short-term treatment of plantar fasciitis.

\section{Conflict of Interest: None}

\section{References}

1. Batt, Mark, Janji. Management Options for Plantar Fasciitis. The Physician and Sports Medicine 1995; 23(6): 77-85.

2. Sobel E, Levitz S J. Update on Plantar Fasciitis, Diagnosis, Management and Currents Treatments. Podiatry Management. April/ May 2001 ( 100-112).

3. Middleton JA, Koldin EL. Plantar fasciitis- Heel Pain in Athletes. Jr of Athletic Training 1992; 27(1): 70-75.

4. Martin JE, Hosch CJ, Lynch DM et al. Mechanical Treatment of Plantar Fasciitis. Jr Am Podiatry Med Assoc 2001; 91(2): 55-62.

5. Lemont $\mathrm{H}$, Amminrati MK, Usen N. Plantar Fasciitis. A Degenerative Process (Fasciosis) without Inflammation. Jr Am Podiatry Med Assoc 2003: 93(3): 234-37.

6. Kibler WB, Goldberg C, Chandler TJ. Functional Biomechanics Deficits in Running Athletes with Plantar Fasciitis. The American Orthopaedic Society For Sports Med 1991; 19(1): 66-71.

7. Young CC, Rutherford DS, Niedfeldt MW. Treatment of Plantar Fasciitis. Am Fam Physician 2001; (63): 467-74, 477-78.

8. Dubin J. Evidence Based Treatment for Plantar Fasciitis. Sports Therapy (3) 2007.

9. Kwong PK, Kay D, White MW. Plantar Fasciitis: Mechanics and Pathomechanics of Treatment. Clinics in Sports Med 1998; 7(1).

10. Riddle DL, Pulisic M, Johnson RE. Risk Factors for Plantar Fasciitis; A Matched Case-Control Study. The Jr Of Bone And Joint Surgery 2003; (85): 872-877.

11. Riddle DL, Freeman D B. Management of a Patient with a Diagnosis of Bilateral Plantar Fasciitis and Achilles Tendinitis: A Case Report. Physical Therapy 1998; 68(12).

12. Stuber K, Kristmanson K. Conservative Therapy for Plantar Fasciitis: A Narrative Review of Randomized Controlled Trials. The Jr. of Canadian Chiropractic Assoc 2006; 50(2).

13. Landorf KB, Radford JA, Keenan AM et al. Effectiveness of Low-Dye Taping for the Short-Term Management of Plantar Fasciitis. Jr Am Podiatr Med Assoc 2005; 95 (6); 525-530.

14. Radford JA, Landorf KB, Buchbinder R et al. Effectiveness Of Low-Dye Taping For The Short-Term Treatment Of Plantar Heel Pain: A Randomized Trial. BMC Musculoskeletal Disorder 2006; 7: 64.

15. Keenan AM, Tanner C M. The Effect Of High- Dye And Low- Dye Taping On Rearfoot Motion. Jr Am Podiatry Med Assoc 2001; 91(5): 255-261.

16. Hlavac HF. The Foot Book. Mountain View, C A .W. 
Publications 1997,( ISBN 0-89037-119-9).

17. Hyland MR, Gaffney AW, Cohen L et al. Randomized Controlled Trial of Calcaneal Taping, Sham Taping and Plantar Fascia Stretching for the Short-Term Management of Heel Pain. Jr Orthop Sports Phys Ther 2006; 36(6): 364-371.

18. Ryan ED, Herda TJ, Coster PB et al. Determining the Minimum Number of Passive Stretches Necessary to Alter Musculotendinous Stiffness. Jr Of Sports Sciences 2009; 27(9): 957-961.

19. Kuhar S, Subhash K, Chitra J. Effectiveness of Myofascial Release in Treatment of Plantar Fasciitis. Indian Journal of Physiotherapy and Occupational Therapy 2007; 1(3).

20. Lange L, Chipchase, Evans A. The Effect of Low-Dye Taping on Plantar Pressure during Gait, in Subject with Navicular Drop Exceeding 10mm: Jr Orthop Sports Phys Therapy 2004; 34(4).

21. Pollard H. Management of Plantar Fasciitis; A Case reports. Sports Chiropractic and Rehabilitation 1999; 13(3): 93-97.

22. Hintermann B, Nigg BM. Pronation In Runners: Implication For Injuries. Sports Med 1998; 26: 169-176.

23. Price DD, Bush FM, Long $S$ et al. A Comparison of Pain Measurement Characteristics of Mechanical Visual Analogue and Simple Numerical Rating Scales. Pain 56 (1994); 217-226.

24. Mark EB, Conrad KJ, Roach K E. The Foot Function Index: A Measure of Foot Pain and Disability. Jr Clin Epidmiol 1991; 44(6): 561-570.

25. McPoil TG, Martin RL et al. Heel Pain Plantar - Fasciitis. Jour Ortho Sports Phy Therapy 2008: 38(4).

26. Bartold SJ. The Plantar Fascia as a Source of Pain Biomechanics, Presentation and Treatment. Jr of Bodywork and Movement Therapies 2004: 8; 214-226.

27. Vicenzino B, Feilding J, Howard R et al. An Investigation of the Antipronation Effect of Two Taping Methods after Application and Exercise. Gait And Posture 1997; (5): 1-5.

28. Digivanni BF, Nawoczenski DA, Baumhauer JF. TissueSpecific Plantar Fascia- Stretching Exercise Enhance Outcomes in Patients with Chronic Heel Pain: A Randomized Study. The Jr of Bone and Joint Surgery 2003; 85(7).

29. Costa IA, Dyson A. The Integration of Acetic Acid Iontophoresis, Orthotic Therapy and Physical Rehabilitation for Chronic Plantar Fasciitis: A Case Study. J Can Chiropr Assoc 2007; 51(3).

30. Crawford F, Snaith M. How Effective Is Therapeutic Ultrasound in the Treatment of the Heel Pain? Annals of the Rheumatic Disease 1996; 55: 265-267.

31. Vincenzino B, Franerhowich M, Mcpoil T et al. Initial Effects of Anti-Pronation Tape on the Medial Longitudinal Arch during Walking and Running. British
Jr of Sports Med 2005; 39: 939-943.

32. Knight CA, Rutledge CR, Cox ME et al. Effect of Superficial Heat, Deep Heat, and Active Exercise Warm-up on the Extensibility of the Plantar Flexors. Physical Therapy 2001; 81(6). 